\title{
Adulteration of raw milk in the rural areas of Barisal district of Bangladesh
}

\author{
T Chanda', GK Debnath ${ }^{2}$, ME Hossain ${ }^{3}$, MA I slam¹, MK Begum ${ }^{4}$
}

${ }^{1}$ Department of Dairy and Poultry Science, Faculty of Animal Science and Veterinary Medicine, Patuakhali Science and Technology University; ${ }^{2}$ Department of Dairy and Poultry Science ${ }^{3}$ and Department of Animal Science and Nutrition, Faculty of Veterinary Medicine, Chittagong Veterinary and Animal Science University;

${ }^{4}$ Department of Basic Science, Faculty of Animal Science and Veterinary Medicine, Patuakhali Science and Technology University

\begin{abstract}
The study was undertakento detect the type of adulterants and preservatives added to the incoming fluid milk from rural areas to the Barisal city of Bangladesh. Total fifty milk samples were collected from five different entry points of Karapure, Dabdopia, Shaestabad, Goriarpar and Khanpura of Barisal district where ten samples were taken from each entry point. The results indicated that, $100 \%$ of the milk samples were adulterated with water irrespective of collection points and months. Cane sugar, powdered milk and starch were detected as $26.0,14.0$ and $12.0 \%$ in the milk samples, respectively. Two types of preservatives namely formalin and sodium bicarbonate were detected in the fluid milk from the study areas. Out of all samples, $10.0 \%$ was adulterated with formalin and $20.0 \%$ with sodium bicarbonate. However, none of the samples contained either hydrogen peroxide or borax. There was a positive relationship between day temperature and intensity of adding preservatives to the fluid milk. As the day temperature increased, the number of preservative positive samples also increased in a linear fashion and vice versa. It could therefore be inferred that, the consumers need to be more cautious regarding the quality of raw milk specially in summer season.
\end{abstract}

Key words: Adulteration, raw milk, water, cane sugar, powdered milk, formalin, sodium bicarbonate Bangladesh Animal Husbandry Association. All rights reserved. Bang. J. Anim. Sci. 2012. 41 (2): 112-115

\section{Introduction}

Milk has been the quality of unique food for nourishment of human being long before recorded history. It is well known that milk is 'almost complete' as like as any other wholesome nutritious food for all mammals including human being. Milk in its natural form has the apex food value. It supplies nutrients like high quality protein, fat, carbohydrate, vitamin and mineral in significant amount than any other single food (Neumann et al. 2002). However, the quality of milk is deteriorated due to adulteration in different marketing channels. Adulteration of milk is usually done by adding inferior cheaper materials or elements like pond water, cane sugar and powdered milk (Prasad 1999). Milk is a very perishable product and its shelf life is few hours. Health hazard chemicals are frequently used to the milk in different regions of Bangladesh as preservative for increasing its shelf life and though LP-system is safe preservative for increasing the shelf life of milk (FAO 1999), nobody is using this preservative in Bangladesh except some milk shed areas where market milk companies have been collecting milk. Human

${ }^{*}$ Corresponding Author: gkdebnath@yahoo.com population of Barisal city is 328278 (BBS 2011) but the amount of milk production in and around the city is very negligible against the demand. Therefore, the major portion of milk usually comes from rural areas. Limited works have been done in different regions of Bangladesh regarding public health issues relating to adulteration of raw milk. Therefore, present study was undertaken to determine the type of adulterants and preservatives added to raw milk by the suppliers from rural areas of Barisal city.

\section{Materials and Methods}

\section{Selection of collection points}

The different entry points of fluid raw milk coming from rural areas to Barisal city were identified and most important five of them were selected. The selected entry points were Karapure, Dabdopia, Shaestabad, Goriarpar and Khanpura of Barisal district.

\section{Recording of temperature}

The ambient temperature of the milk collection points were recorded directly from different surrounding points of the study areas by using 
thermometer. Temperature was recorded from morning to evening and the mean values were calculated from the recorded values.

\section{Duration of study}

The study was undertaken for a period of five months from August to December 2010. As a study period, August month was selected for recording high ambient temperature and December was selected for recording low ambient temperature.

\section{Collection of sample}

Total 50 samples were collected. Ten samples were taken from each entry point. Two samples were collected per month per point to observe the effect of temperature on preservative content of milk.

\section{Sampling of fluid milk}

The samples were collected from bulk sources of fluid milk through proper mixing with the help of a plunger \& dipper. Immediate after collection, the samples were kept into the cool box for ceasing the growth and activity of acid producing organisms.

\section{Chemical tests}

The type of adulterants and preservatives added to the fluid milk was detected by using chemical tests. All tests were conducted in the Dairy Science Laboratory, Faculty of Animal Science and Veterinary Medicine, Patuakhali Science and Technology University as per DGHS (2005).

\section{Data analyses}

The data related to laboratory tests and ambient temperature were recorded, compiled and processed in Microsoft excel 2007. Data were analyzed by using Chi-square test. Relationship between ambient temperature and addition of formalin or sodium bicarbonate were estimated by using Pearson's correlation coefficient ' $r$ '. Coefficient of determination $R^{2}$ was estimated by using least square regression method. Statistical significance was accepted at $p<0.05$.

\section{Results and Discussion}

The adulterant in raw milk collected from different points of Barishal district are presented in Table 1. All samples collected from five different entry points were adulterated with water throughout the whole study period. Water as adulterant in milk could be due to the convenience of its mixing to increase the volume and also to neutralize the developed acidity of fluid milk for prolonged shelf life. Cane sugar was detected as adulterant by $40.0 \%$ of the milk samples collected from Karapure and Shaestabad. On an average, 26.0\% of the sample was detected as cane sugar positive. Exact reason for incorporation of cane sugar in raw milk is unknown. However, sugar is cheap source of sweetener. Therefore, it could be assumed that cane sugar is added to the diluted raw milk to improve its taste.

Powdered milk was detected by $14.0 \%$ of all samples. However, maximum $30.0 \%$ of the milk samples collected from Shaestabad was found to be adulterated with powdered milk. Interestingly, samples collected from Khanpura and Dapdopia were totally free from adulteration of powdered milk. Non-fat powdered milk is comparatively cheaper than full fat milk. Possible reasons for incorporation of low quality powdered milk could be to increase the solid portions of diluted milk. Starch was detected in $12.0 \%$ of all samples. Maximum $30.0 \%$ of the milk samples collected from Karapure were contaminated with starch. However, samples collected from Goriarpara and Khanpura were totally free from adulteration of starch.

Besides water, the common adulterants in most of the sample were cane sugar, powdered milk and starch. The reason could be that, solid materials like starch, cane sugar and powder milk might increase the concentration of diluted milk, the volume of which has already been increased by adding water by the middlemen to maximize their profit. This result is in agreement with the findings of Lateef et al. (2009) who found that middlemen used to adulterate milk to maximize their profit by adding cheap substances to increase the value of total solids up to a level which is acceptable by the consumers.

In raw milk, chemicals like formalin, hydrogen peroxide, boric acid and various antibiotics are added to increase the shelf life. In the present study, milk samples were tested for detecting borax, hydrogen per oxide, sodium bicarbonate and formalin. On average, $20 \%$ of the milk samples were detected as sodium bicarbonate positive (Table 2 ) and $10 \%$ of the milk samples were detected as formalin positive. Hydrogen peroxide and borax were not detected in any sample of the study area. This result is a bit different from the findings of Debnath et al. (2009) and Das et al. (2010) who found only formalin as added preservative in raw milk in Chittagong metro-politan area. 


\section{Adulteration of raw milk}

Table 1. Presence of adulterant (\% positive sample) in the raw milk collected from different points of Barisal district $(\mathrm{N}=50)$

\begin{tabular}{llllllll}
\hline Adulterant & Karapure & Dabdopia & Shaestabad & Goriarpar & Khanpura & Average & Sig. level \\
\hline Water & 100.0 & 100.0 & 100.0 & 100.0 & 100.0 & 100.0 & NS \\
Cane sugar & 40.0 & 20.0 & 40.0 & 10.0 & 20.0 & 26.0 & $* *$ \\
Powdered milk & 20.0 & 0.0 & 30.0 & 20.0 & 0 & 14.0 & $* *$ \\
Starch & 30.0 & 20.0 & 10.0 & 0 & 0 & 12.0 & $* *$ \\
\hline
\end{tabular}

NS, non-significant $(p>0.05) ;{ }^{* *}, p<0.01$

Table 2. Presence of preservatives (\% positive sample) in the raw milk collected from different points of Barisal district $(\mathrm{N}=50)$

\begin{tabular}{llllllll}
\hline Preservatives & Karapure & Dabdopia & Shaestabad & Goriarpar & Khanpura & Average & Sig. level \\
\hline Sodium bicarbonate & 40.0 & 30.0 & 10.0 & 20.0 & 0 & 20.0 & $* *$ \\
Formalin & 0 & 10.0 & 40.0 & 0 & 0 & 10.0 & $* *$ \\
Hydrogen peroxide & 0 & 0 & 0 & 0 & 0 & 0 & NS \\
Borax & 0 & 0 & 0 & 0 & 0 & 0 & NS \\
\hline
\end{tabular}

NS, non-significant $(p>0.05) ;{ }^{* *}, p<0.01$

Table 3. Relationship between ambient temperature and addition of formalin and sodium bicarbonate or no preservative

\begin{tabular}{lllll}
\hline Temperature & Formalin & Sodium bicarbonate & No preservative & Sig. level \\
\hline August $\left(35^{\circ} \mathrm{C}\right)$ & 30.0 & 20.0 & 50.0 & $* *$ \\
September $\left(30^{\circ} \mathrm{C}\right)$ & 20.0 & 30.0 & 50.0 & $* *$ \\
October $\left(27^{\circ} \mathrm{C}\right)$ & 0 & 30.0 & 70.0 & $* *$ \\
November $\left(23^{\circ} \mathrm{C}\right)$ & 0 & 20.0 & 80.0 & $* *$ \\
December $\left(19^{\circ} \mathrm{C}\right)$ & 0 & 0 & 100.0 & $* *$ \\
Sig. level & $* *$ & $* *$ & $* *$ & \\
\hline
\end{tabular}

${ }^{\#}$ Formalin, sodium bicarbonate; ${ }^{* *}, \mathrm{p}<0.01$

There was a positive relationship between day temperature and intensity of using chemicals as preservative (Table 3; Figure 1, 2 and 3). The day temperature was highest in August $\left(35^{\circ} \mathrm{c}\right)$ and at the same time percentage of preservative detected samples were also highest. The day temperature was lowest in December $\left(19^{\circ} \mathrm{C}\right)$ during the experimental period and at the same time no preservative was used for increasing the shelf life of milk. In fact, there was a decreasing trend of day temperature from September as a result propensity of adding preservatives to milk also decreased. This result clearly indicates that the suppliers added preservatives to save milk from souring due to higher ambient temperature.

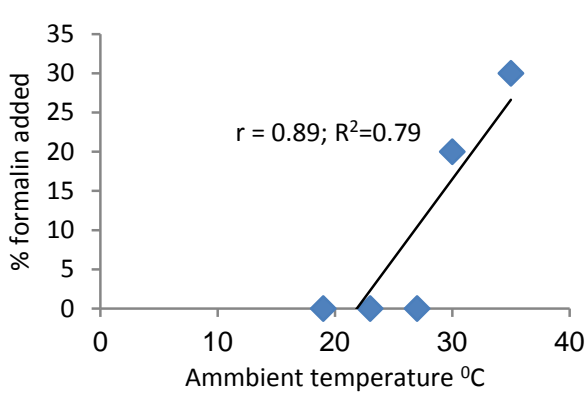

Figure 1. Relationship between ambient temperature and formalin \% in raw milk

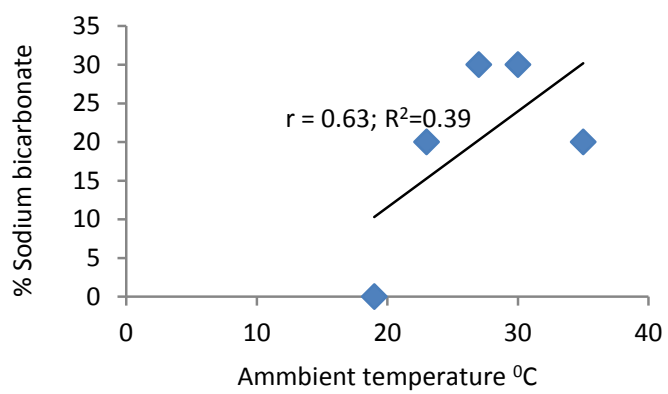

Figure 2. Relationship between ambient temperature and sodium bicarbonate $\%$ in raw milk

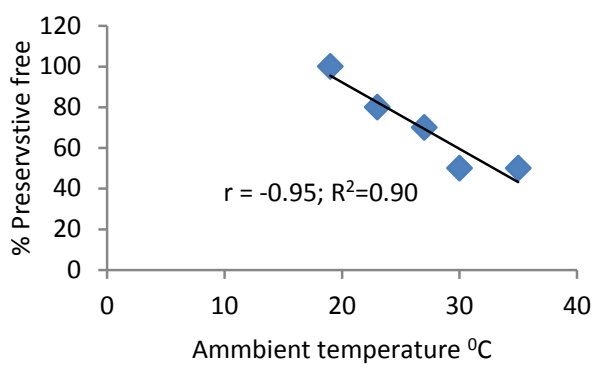

Figure 3. Relationship between ambient temperature and $\%$ preservative free in raw milk 


\section{Conclusion}

In the light of above discussion, it may be concluded that, the water was the most common adulterant in all samples of raw milk collected irrespective of months and collection points. Other adulterants were cane sugar, powdered milk and starch. Formalin and sodium-bicarbonate were detected as the common preservative. There was a positive relationship between ambient temperature and the use of formalin and sodiumbicarbonate. The frequency of adding preservatives gradually decreased in a linear fashion with decreasing day temperature and the vice versa as seasonal effect.

\section{References}

BBS (2011). Bangladesh Bureau of Statistics. Statistics and maps for divisions, districts, cities, municipalities, urban areas and metropolitan areas in Bangladesh.

Das S, Debnath GK, Chanda T, Alim MA and Sarker S ( 2010). A study on quality of milk from farm to shop in Chittagong Metropolitan area. Int. J. Anim. Fish. Sci., 3: 252-256.

Debnath GK, Kober, AKM and Chanda GC (2008). Quality of fluid milk available in Chittagong Metropolitan area. In: Debnath
NC, Khan KI, Hossain ME, Barua $\mathrm{H}$, Alam $\mathrm{R}$, Ahmed SSU and Hossain S (eds.). Proc. $6^{\text {th }}$ Sci. Con. 4-6 March, Khulshi, Chittagong, Bangladesh. P. 178-182.

DGHS (2005). Directorate General of Health Service. Manual of methods of analysis of foods (milk and milk products). Ministry of health and family welfare, India. P. 1-18.

FAO (1999). Food and Agriculture Organization of the United Nations. Manual on the use of the LP-system in milk handling and preservation. Animal Production Service, FAO Animal Production and Health Division, Rome, Italy.

Prasad J, Tyagi AK and Neeraj (1999). Principles and Practices of Animal Nutrition. $1^{\text {st }}$ edn., Kalyani Publishers, New Delhi-110002.

Lateef M, Faraz A, Mustafa MI, Akther P, and Bashir MK (2009). Detection of adulterants and chemical composition of milk supplied to canteens of various hospitals in Faisalabad city. Pak. J. Zool. Suppl., 9: 139-142.

Neumann CG, Harris DM and Rogers LM (2002). Contribution of animal source foods in improving diet quality and function in children in the developing world. Nutr. Res. 22: 193-220. 